\title{
Transient anoxia and oxyradicals induce a region-specific activation of MAPKs in the embryonic heart
}

\author{
Stephany Gardier $\cdot$ Sarah Pedretti $\cdot$ \\ Alexandre Sarre $\cdot$ Eric Raddatz
}

Received: 26 August 2009/Accepted: 26 February 2010/Published online: 21 March 2010

(C) Springer Science+Business Media, LLC. 2010

\begin{abstract}
We have previously reported in the early septating embryonic heart that electromechanical disturbances induced by anoxia-reoxygenation are distinct in atria, ventricle, and outflow tract, and are attenuated in ventricle by opening of mitochondrial $\mathrm{K}_{\mathrm{ATP}}$ ( mitoK $_{\mathrm{ATP}}$ ) channels. Here, we assessed the regional activation of mitogenactivated protein kinases (MAPKs) ERK, p38, and JNK in response to anoxia-reoxygenation and $\mathrm{H}_{2} \mathrm{O}_{2}$. Hearts isolated from 4-day-old chick embryos were subjected to 30-min anoxia and 60-min reoxygenation or exposed to $\mathrm{H}_{2} \mathrm{O}_{2}(50 \mu \mathrm{M}-1 \mathrm{mM})$. The temporal pattern of activation of ERK, p38, and JNK in atria, ventricle, and outflow tract was determined using immunoblotting and/or kinase assay. The effect of the mitoK $\mathrm{ATP}_{\mathrm{AT}}$ channel opener diazoxide $(50 \mu \mathrm{M})$ on JNK phosphorylation was also analyzed. Under basal conditions, total ERK and JNK were homogeneously distributed within the heart, whereas total p38 was the lowest in outflow tract. The phosphorylated/total form ratio of each MAPK was similar in all regions. Phosphorylation of ERK increased in atria and ventricle at the end of reoxygenation without change in outflow tract. Phosphorylation of p38 was augmented by anoxia in the three regions, and returned to basal level at the end of reoxygenation except in the outflow tract. JNK activity was not altered by anoxia-reoxygenation in atria and outflow tract. In ventricle, however, the diazoxide-inhibitable peak of JNK activity known to occur during reoxygenation was
\end{abstract}

S. Gardier · S. Pedretti - A. Sarre · E. Raddatz Department of Physiology, Faculty of Biology and Medicine, University of Lausanne, Lausanne, Switzerland

S. Gardier $(\bowtie)$

Faculty of Medicine, University of Geneva, 1 Rue Michel

Servet, 1211 Geneve 4, Switzerland

e-mail: stephany.gardier@hcuge.ch not accompanied by a change in phosphorylation level. $\mathrm{H}_{2} \mathrm{O}_{2}$ over $500 \mu \mathrm{M}$ impaired cardiac function, phosphorylated ERK in all the regions and p38 in atria and outflow tract, but did not affect JNK phosphorylation. At a critical stage of early cardiogenesis, anoxia, reoxygenation, exogenous $\mathrm{H}_{2} \mathrm{O}_{2}$ and opening of mitoK $\mathrm{K}_{\text {ATP }}$ channels can subtly modulate ERK, p38, and JNK pathways in a region-specific manner.

Keywords p38 MAP kinase - ERK · JNK · Anoxia-reoxygenation · Embryonic heart - Oxyradicals

\section{Introduction}

The embryonic/fetal heart develops and operates normally in a relatively hypoxic intrauterine environment, but reacts rapidly to oxygen lack [1-3]. Oxygen deprivation during critical periods of embryogenesis impairs heart development and function, resulting in growth retardation and increasing the risk of cardiovascular disease in adulthood [4-6]. Maternal hypoxemia, reduction in umbilical blood flow or placental dysfunction can rapidly lead to acute or chronic ischemia and/or hypoxia. Although the postischemic fetal heart seems to recover faster than the adult heart $[7,8]$, the tolerance of the embryonic heart to hypoxia and its capacity to recover during reoxygenation remain under debate. Moreover, the functional and developmental consequences of oxygen lack may vary from one cardiac region to another since the tissue properties and the fate of each part of the heart are different. Atria differentiate at older stages into pacemaker tissue, ventricle into working myocardium and outflow tract into aorta and pulmonary artery. In previous works, we have precisely characterized the electrical and contractile disturbances induced by 
anoxia and reoxygenation in the heart isolated from 4-dayold chick embryos [9, 10]. Arrhythmias and myocardial stunning observed at reoxygenation are associated with a burst of reactive oxygen species (ROS) [9], and recovery of excitation-contraction coupling in the ventricle is improved by pharmacological activation of the mitochondrial $\mathrm{K}_{\mathrm{ATP}}\left(\right.$ mitoK $\left._{\mathrm{ATP}}\right)$ channels, via PKC, NO-, and ROSdependent mechanisms. However, the signaling pathways underlying the response to anoxia-reoxygenation remain unclear in the embryonic heart.

Mitogen-activated protein kinases (MAPKs), which belong to a highly conserved family of serine/threonine kinases, are present in all eukaryotic cells and are signaling proteins that play a key role in response to a wide range of stress [11]. The three best-characterized MAPKs, extracellular signal-regulated protein kinase (ERK), c-jun $\mathrm{NH}_{2}$-terminal kinase (JNK), and p38 MAPK have been involved in a vast array of physiopathological mechanisms in cardiac cells [12-15], and are notably implicated in ischemia-reperfusion injury and in pre- and post-conditioning mechanisms [16-19]. Previous studies, mainly focused on newborn or adult models [12], have reported conflicting data, and the involvement of MAPKs pathways in the response of the fetal heart to limiting oxygen levels has been poorly investigated. We have recently shown in the ventricle of the embryonic chick heart that JNK pathway is involved in the response to anoxia-reoxygenation and that reoxygenation-induced peak of JNK activity was ROS-independent and tightly related to the open-state of the mitoK $\mathrm{ATP}_{\mathrm{AT}}$ channel [20]. Regarding the response to oxygen deprivation and reoxygenation, some differential sensitivity is expected within the embryonic heart since anoxic tolerance [9], energy metabolism [21], $\mathrm{Ca}^{2+}$ handling [22, 23], myofilaments [24], oxidative stress [25], sensitivity to NO [26], and electrical [27] and contractile [10] properties vary from one cardiac region to another. These important developmental, structural, and functional differences combined with the fact that activation of MAPKs depends on the nature of the stimuli and the celltype [28] lead us to hypothesize that ERK, p38, and JNK pathways display distinct spatio-temporal patterns of activation in response to a transient anoxic stress. The main goal of the present work was to investigate the expression and the profile of activation of ERK, p38, and JNK in atria, ventricle and outflow tract of the embryonic heart submitted to anoxia, reoxygenation, and oxidant stress.

\section{Methods}

\section{Reagents}

All standard chemicals, as well as dimethylsulfoxide (DMSO), hydrogen peroxide $\left(\mathrm{H}_{2} \mathrm{O}_{2}\right)$, and mitoK $_{\mathrm{ATP}}$ channel opener diazoxide were analytical grade and purchased from Sigma-Aldrich. $\left[\gamma^{33} \mathrm{P}\right]$ ATP was from Amersham Biosciences and inhibitors of proteases from Roche Biosciences. Rabbit antibodies against phosphorylatedERK1/2, phosphorylated-p38, phosphorylated-JNK1/2, total-ERK1/2, total-p38, total-JNK1/2 were purchased from Cell Signaling Technology. The antibody against $\alpha$-actin was from Sigma-Aldrich and the secondary antibody (goat anti-rabbit HRP conjugated) was from GE Healthcare. The enhanced chemiluminescence (ECL) western blot reagent kit was from Pierce and the films from GE Healthcare.

Preparation and in vitro mounting of the heart

Because of the minute size of the heart (circa $60 \mu \mathrm{g}$ proteins) and its parts at the stage investigated, a total of about 1000 chick embryos were utilized in this study. All experiments were performed in accordance with the guidelines of the local veterinary authority. Fertilized eggs from Lohman Brown hens were incubated during $96 \mathrm{~h}$ at $38^{\circ} \mathrm{C}$ and $95 \%$ relative humidity to obtain stage $24 \mathrm{HH}$ embryo (according to Hamburger and Hamilton [29]). The spontaneously beating hearts were carefully excised from explanted embryos by section at the level of the truncus arteriosus as well as between the sinus venosus and the atria. The hearts were then placed in the culture compartment of an airtight chamber.

The stainless steel chamber was equipped with two windows for observation and maintained under controlled conditions on the thermostabilized stage $\left(37.5^{\circ} \mathrm{C}\right)$ of an inverted microscope (IMT2 Olympus, Tokyo, Japan) as previously detailed [10]. Briefly, the culture compartment (300 $\mu \mathrm{l})$ was separated from the gas compartment by a $15 \mu \mathrm{m}$ transparent and gas-permeable silicone membrane (RTV 141, RhônePoulenc, Lyon, France). Thus, $\mathrm{pO}_{2}$ at the tissue level could be strictly controlled and rapidly modified (within less than $5 \mathrm{~s}$ ) by flushing high-grade gas of selected composition through the gas compartment. At this developmental stage, the heart lacks vascularization and the myocardial oxygen requirement is met exclusively by diffusion.

The culture medium was standard $\mathrm{HCO}_{3} / \mathrm{CO}_{2}$ buffered Tyrode medium, equilibrated in the chamber with $2.31 \%$ $\mathrm{CO}_{2}$ in air (normoxia and reoxygenation) or in $\mathrm{N}_{2}$ (anoxia) yielding a $\mathrm{pH}$ of 7.4. Diazoxide was diluted in this medium containing $0.5 \%$ DMSO (vehicle) and present throughout the experimental protocol.

Anoxia-reoxygenation protocol

After a 30 min preincubation at room temperature in vehicle or in diazoxide $(50 \mu \mathrm{M})$, hearts were mounted in vitro and stabilized 45 min under normoxia at $37^{\circ} \mathrm{C}$, and then submitted to strict anoxia during $30 \mathrm{~min}$, followed by 
60 min of reoxygenation. The hearts were harvested after the period of normoxic stabilization, after $30 \mathrm{~min}$ of anoxia and after 10, 30, and $60 \mathrm{~min}$ of reoxygenation. Atria, ventricle, and outflow tract of each heart were carefully dissected on ice and stored at $-80^{\circ} \mathrm{C}$ for subsequent determinations.

\section{Hydrogen peroxide $\left(\mathrm{H}_{2} \mathrm{O}_{2}\right)$ exposure}

The hearts were placed in a Petri dish in the standard medium, stabilized 45 min under normoxia and then exposed $1 \mathrm{~h}$ to $50,100,200,500$ or $1000 \mu \mathrm{M}$ of $\mathrm{H}_{2} \mathrm{O}_{2}$ at $37^{\circ} \mathrm{C}$. Cardiac rhythmicity and contractility were not different in hearts cultured in Petri dishes or in hearts mounted in culture chamber. The critical $\mathrm{H}_{2} \mathrm{O}_{2}$ concentration that impaired cardiac function was obtained by determining the proportion of hearts still beating at the end of each experiment. Atria, ventricle, and outflow tract were then carefully dissected on ice and stored at $-80^{\circ} \mathrm{C}$ for subsequent determinations.

\section{Protein extract preparation}

Atria, ventricles, and outflow tracts were homogenized by sonication $3 \times 2 \mathrm{~s}$ in the ice-cold lysis buffer. For each sample six atria, three ventricles, and six outflow tracts were pooled. Insoluble material was removed by $5 \mathrm{~min}$ centrifugation at $10,000 \times g$ and protein content was measured by the method of Bradford (Coomassie protein assay kit, Pierce) with bovine serum albumin as standard.

\section{Immunoblotting}

Proteins from whole cellular extracts $(20 \mu \mathrm{g})$ were boiled with 33 vol.\% of SDS sample buffer, separated on 10\% SDSpolyacrylamide gels, and transferred to nitrocellulose membranes, which were probed with primary antibodies against MAPKs (1:1000) or against $\alpha$-actine (1:5000) diluted in $5 \%$ bovine serum albumin in TBS-T (overnight, $4^{\circ} \mathrm{C}$ ). The blots were then incubated ( $1 \mathrm{~h}$, room temperature) with secondary antibody (1:10000) in $1 \%$ non-fat milk powder in TBS-T. Immunoreactive bands were detected with enhanced chemiluminescent procedure using SuperSignal West Dura Extended Duration Substrate (Pierce, Rockford, IL, USA). The signal was semi-quantitatively analyzed using scanning densitometry (Quantity-One software, Biorad).

Protein bands were normalized to total-MAPKs or $\alpha$-actin content in the same sample. In turn, the resulting densitometric ratio obtained during anoxia and reoxygenation was normalized to an internal control (the respective preanoxic ratio), and reported as fold increase. Thus, all the values $>1$ indicate a level of phosphorylation higher than the preanoxic level.
Kinase assay

JNK activity was determined according to a published method [30] with minor modifications [20]. Soluble protein extracts $(30 \mu \mathrm{g})$ were incubated for $3 \mathrm{~h}$ at $4^{\circ} \mathrm{C}$ in the presence of $1 \mu \mathrm{g}$ GST-c-Jun ${ }_{(1-219)}$ bound to glutathioneagarose beads as both JNK-specific ligand and substrate. The beads were washed three times in washing buffer, and twice in kinase buffer. Kinase reaction was carried out for $30 \mathrm{~min}$ at $30^{\circ} \mathrm{C}$ in $20 \mu \mathrm{l}$ of kinase buffer containing $5 \mu \mathrm{Ci}$ $\left[\gamma-{ }^{33} \mathrm{P}\right]$ ATP. Reaction products were resolved by $12 \%$ SDS-polyacrylamide gel electrophoresis, gels were dried, and phosphorylation signals were visualized by autoradiography and quantitated by PhosphoImager (Quantity-One 1.4.0, Biorad) and normalized to the respective preanoxic control level.

\section{Statistical analysis}

Results are given as mean \pm standard error of the mean (SEM). Statistical analysis was performed using Statistica 8.0 Software. Differences between time-points were determined by Kruskal-Wallis test followed by multiple comparisons post-hoc test. The significance of any difference between two conditions was assessed by MannWhitney test. The statistical significance was defined by a value of $P \leq 0.05$.

\section{Results}

Inhomogeneous MAPKs distribution under basal conditions

Under basal conditions (i.e., just dissected heart) the content of total form of ERK (p42) and JNK (p54) was similar in the three regions of the heart (Fig. 1a, b). However, in the outflow tract, the content of total form of p38 was lower than in atria and ventricle, and expression of p46 isoform of JNK was not detectable. In the three regions of embryonic heart p44 isoform of ERK was not expressed.

The phosphorylated to total form ratio of ERK, p38, and JNK was not significantly different in atria, ventricle, and outflow tract (Fig. 1b). Ventricle contained more $\alpha$-actin than atria and outflow tract for the same quantity of protein (Fig. 1c).

Exogenous $\mathrm{H}_{2} \mathrm{O}_{2}$ phosphorylated MAPKs differently in atria, ventricle, and outflow tract

In order to determine to what extent myocardial MAPKs can be stimulated by $\mathrm{H}_{2} \mathrm{O}_{2}$, hearts were exposed to a concentration ranging from $50 \mu \mathrm{M}$ to $1 \mathrm{mM}$. Cardiac 


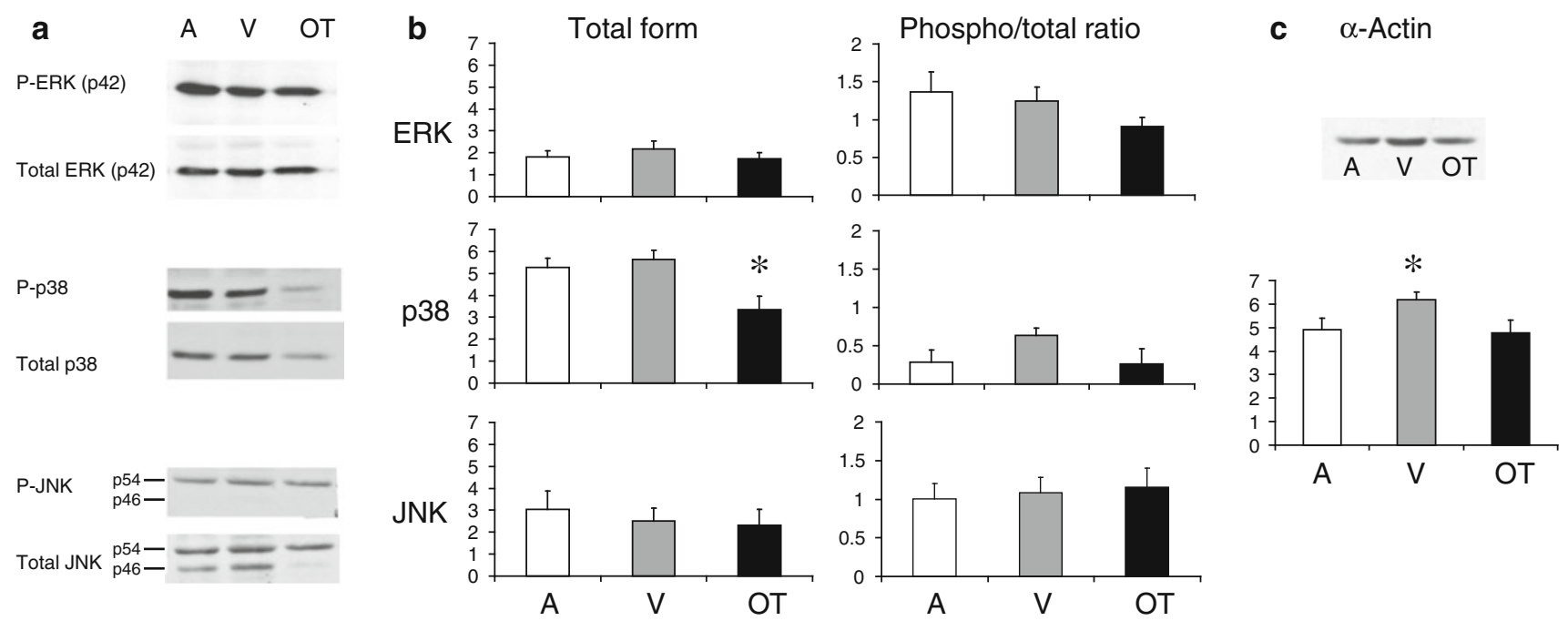

Fig. 1 Basal distribution of MAPKs and actin in atria (A), ventricle (V), and outflow tract (OT) of the embryonic chick heart at stage 24HH. a Representative immunoblots for phosphorylated and total ERK, p38, and JNK. b Densitometric analysis (arbitrary units) of total form and the phosphorylated to total form ratio. c Actin content. Only

function was clearly impaired by $\mathrm{H}_{2} \mathrm{O}_{2}$ at a rather high concentration $(1 \mathrm{mM})$ which was subsequently used to assess its effects on the level of MAPK phosphorylation (Fig. 2a). Compared to controls, $\mathrm{H}_{2} \mathrm{O}_{2}$ promoted ERK phosphorylation in the whole heart, and significantly increased p38 phosphorylation only in atria and outflow tract. Surprisingly, the level of JNK phosphorylation was not altered by $1 \mathrm{mM} \mathrm{H} \mathrm{H}_{2} \mathrm{O}_{2}$, whatever the investigated region (Fig. 2b).

Anoxia-reoxygenation activated MAPKs differently in atria, ventricle, and outflow tract

The Fig. 3 shows the spatio-temporal modulation of the MAPKs in the embryonic heart subjected to anoxia and reoxygenation.

\section{ERK phosphorylation}

ERK phosphorylation increased during reoxygenation in atria and ventricle with a maximum reached at $60 \mathrm{~min}$. In the outflow tract, reoxygenation did not alter significantly ERK phosphorylation.

\section{p38 MAP kinase phosphorylation}

After 30 min of anoxia, the level of p38 phosphorylation was about four-fold higher in the outflow tract than in atria and ventricle. During reoxygenation, the most important variations of $\mathrm{p} 38$ phosphorylation were observed in ventricle with a significant decrease at $60 \mathrm{~min}$. A similar p38 (a, b) and JNKp46 (a) were inhomogeneously expressed. The phospho/total ratio was the lowest for $\mathrm{p} 38$ in the three regions. The content of $\alpha$-actin was the highest in ventricle. The same quantity of protein was loaded in each lane of all the immunoblots $(20 \mu \mathrm{g})$. $n=4-10$ determinations; $* P<0.05$ vs. A or $\mathrm{V}$

phenomenon was observed in the outflow tract but without statistical significance, most probably due to the large variability of the data. It should be noticed, however, that p38 remained activated in the outflow tract throughout reoxygenation, i.e., above its preanoxic level.

JNK activity versus phosphorylation

As determined by kinase assay, JNK activity increased in atria, ventricle, and outflow tract after 30 min of reoxygenation, but not significantly in atria and outflow tract (values reported for the ventricle are taken from our previous work [20]). Surprisingly, in contrast to activity, the level of JNK phosphorylation in the ventricle was not increased by reoxygenation (Fig. 4). Additionally, opening of the mitoK $\mathrm{K}_{\mathrm{ATP}}$ channels by diazoxide markedly reduced ventricular JNK activity during reoxygenation [20] but did not alter the level of phosphorylation (Fig. 4). These data show clearly that JNK activity did not parallel the level of JNK phosphorylation in the embryonic heart.

\section{Discussion}

To the best of our knowledge, this is the first time that distribution and activation of ERK, JNK, and p38 MAPK are explored in the three regions of an embryonic heart model submitted to a transient anoxic stress. Our main findings show that activation of MAPKs can be differentially modulated by anoxia-reoxygenation and by exogenous $\mathrm{H}_{2} \mathrm{O}_{2}$ in a region-specific manner. 
Fig. 2 Effects of $\mathrm{H}_{2} \mathrm{O}_{2}$ on contractile function and MAPKs phosphorylation. a A concentration of $\mathrm{H}_{2} \mathrm{O}_{2}$ higher than $500 \mu \mathrm{M}$ was required to significantly affect contractions of A, V, and OT $(n=100$ hearts). b $\mathrm{H}_{2} \mathrm{O}_{2}$ markedly increased phosphorylation of ERK and p38 specially in A and OT without modifying the level of JNK phosphorylation. Hearts were exposed to $\mathrm{H}_{2} \mathrm{O}_{2} 1 \mathrm{~h}$ at $37^{\circ} \mathrm{C}$. $* P<0.05$ vs. control. $n=5$ determinations a

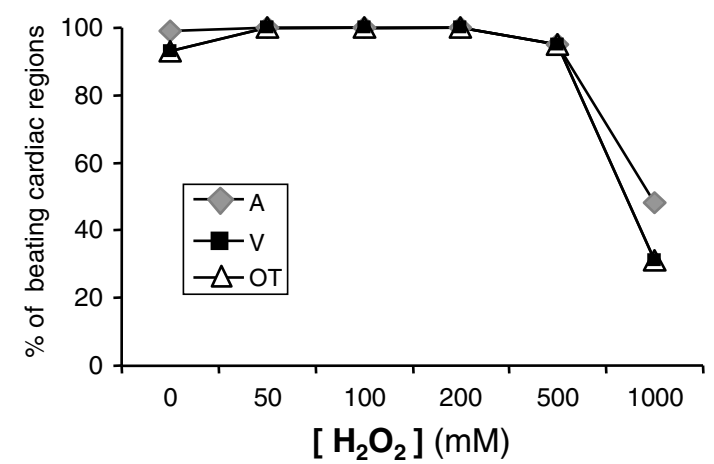

b
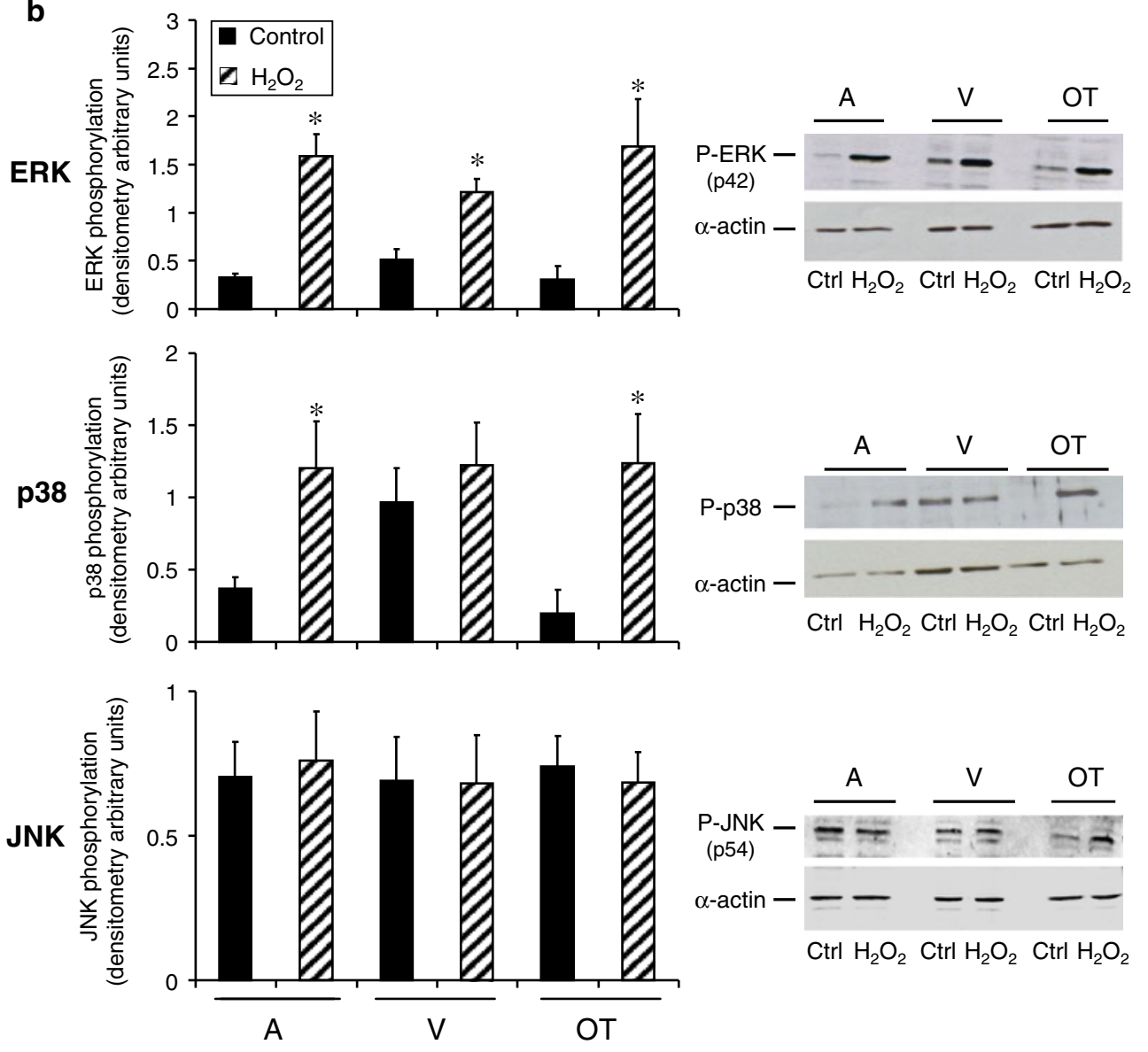

ERK and JNK were homogeneously distributed within the embryonic heart, whereas basal p38 expression was appreciably lower in the outflow tract relative to atria and ventricle (Fig. 1). It should be noticed that only the p42 isoform of ERK was detectable in the embryonic heart (Fig. 1a), alike in the adult chicken heart and different from neonatal and adult murine heart where both p42 and p44 isoforms were identifiable (not shown). Regarding p38 MAP kinase activation, the outflow tract appears also to be a unique part of the embryonic heart since it displayed both the lowest protein expression of p38 and the highest p38 responsiveness to anoxia and reoxygenation (Fig. 3). It should be mentioned that, at the stage investigated $(24 \mathrm{HH})$, the outflow tract undergoes important morphogenetic processes (remodeling) preparing the aorticopulmonary septation [31] which require an important physiological apoptotic activity $[32,33]$. Indeed, in our preparation, there was $8.4 \pm 1.3,9.5 \pm 0.3$, and $14.5 \pm 0.8 \%(n=3$ determinations) of apoptotic cells in atria, ventricle, and outflow tract, respectively (Pedretti and Yang, personal communication). Such a high level of apoptotic activity could partly explain that expression of p38 MAPK, which otherwise has been shown to display anti-apoptotic properties [12, 28], was the lowest in outflow tract. As expected, the highest relative amount of $\alpha$-actin was found in the ventricle and was certainly due to the large number of proliferating and 


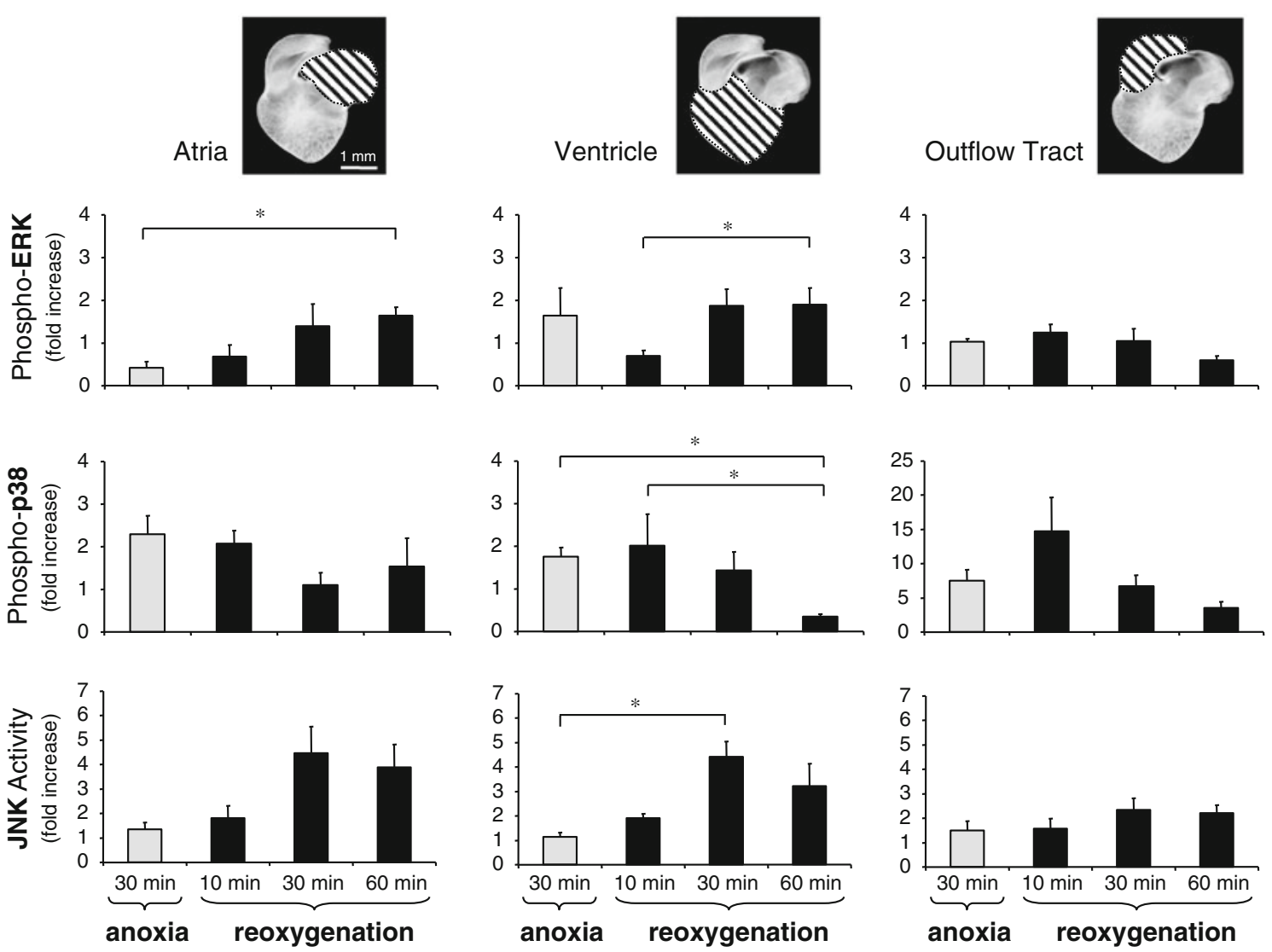

Fig. 3 Phosphorylation level of ERK and p38 MAPK and activity of JNK after $30 \mathrm{~min}$ of anoxia and 10, 30, and $60 \mathrm{~min}$ of reoxygenation in atria, ventricle, and outflow tract (hatched cardiac regions in upper panel). ERK, p38, and JNK displayed a characteristic profile of activation in each investigated region (see text). All values are

differentiating contractile myocytes in the developing compact and trabecular myocardial layers.

It is generally accepted that MAPKs are activated by ROS, especially by hydrogen peroxide $\left(\mathrm{H}_{2} \mathrm{O}_{2}\right)$ [34, 35], although the degree and the time course of activation can differ according to the species, tissue, and cell-type [28, 36]. We sought to determine in atria, ventricle, and outflow tract to what extent exposure to a concentration of $\mathrm{H}_{2} \mathrm{O}_{2}$ sufficient to impair cardiac function, could also activate MAPKs. Under our experimental conditions the cardiac function was not altered by concentration of $\mathrm{H}_{2} \mathrm{O}_{2}<1 \mathrm{mM}$ whereas in fetal, newborn, and adult [37-39] cardiomyocytes contractions are already altered at 0.05 or $0.1 \mathrm{mM} \mathrm{H}_{2} \mathrm{O}_{2}$. Our data and these observations clearly indicate that the embryonic myocardium is less sensitive to this radical than the post-natal myocardium. This is corroborated by the fact that the functional recovery of the embryonic heart is rapidly completed after the reoxygenation-induced burst of ROS [9].

The most important effect of $1 \mathrm{mM} \mathrm{H}_{2} \mathrm{O}_{2}$ on ERK and p38 phosphorylation was observed in atria and outflow expressed as fold increase relative to the preanoxic value obtained after $45 \mathrm{~min}$ of in vitro stabilization. $* P<0.05, n=3-15$ determinations for each column. Values reported for JNK activity in ventricle are taken from our previous work [20]

tract, which is consistent with the fact that $50 \%$ of atria stopped to beat at this concentration of $\mathrm{H}_{2} \mathrm{O}_{2}$ (Fig. 2a) and with the high sensitivity of the outflow tract to oxidative stress [40]. In the ventricle, the reoxygenation-induced peak of JNK activity is ROS-independent [20], and the present data show that JNK phosphorylation was not augmented by $\mathrm{H}_{2} \mathrm{O}_{2}$, whatever the region investigated (Fig. 2), demonstrating that JNK phosphorylation is not modulated even by the high oxidant stress induced by $\mathrm{H}_{2} \mathrm{O}_{2}$ exposure. These observations are in line with data obtained in adult myocardium showing that $\mathrm{JNK}$ is not activated by $\mathrm{H}_{2} \mathrm{O}_{2}$ at concentration as high as $500 \mu \mathrm{M}$ [41] or by exposure to a pro-oxidant hyperoxia [42].

Relative to the other investigated MAPKs, ERK was modestly activated during anoxia and reoxygenation, suggesting that ERK is not a key element of the embryonic heart response to such a stress. ERK being not a stress kinase but mostly associated with cell proliferation and differentiation, it is not surprising that this pathway displayed such minor alteration under our experimental conditions. The low responsiveness of ERK to reoxygenation 


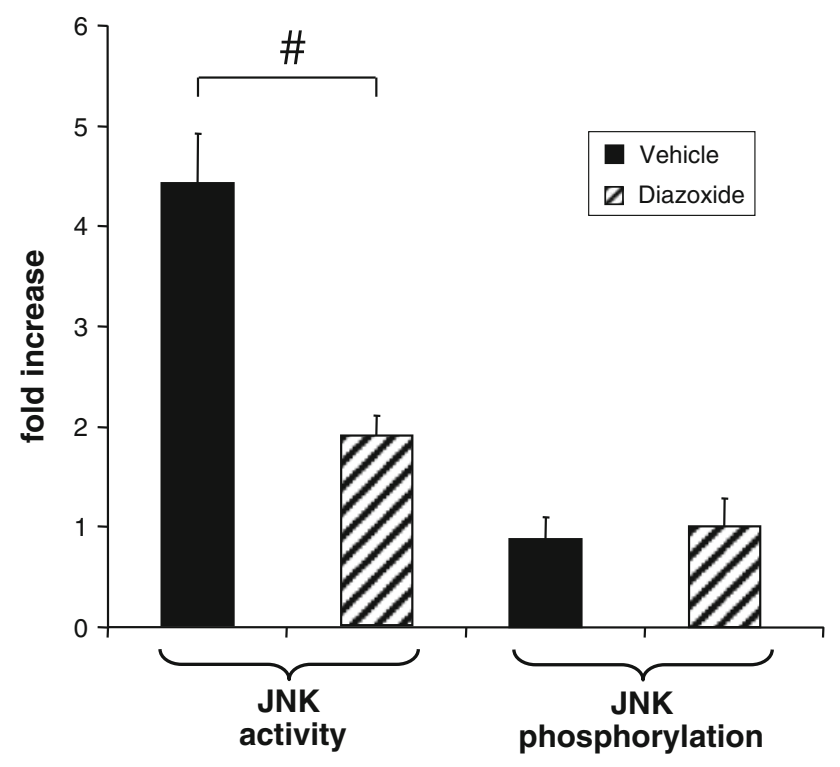

Fig. 4 After 30 min reoxygenation JNK phosphorylation did not parallel JNK activity in the ventricle. Reoxygenation strongly stimulated JNK activity but had no effect on JNK phosphorylation. Pharmacological opening of the mitoK $_{\text {ATP }}$ channel (diazoxide $50 \mu \mathrm{M}$ ) decreased the reoxygenation-induced JNK activity, but did not affect JNK phosphorylation. Values reported for JNK activity are taken from our previous work [20]. All values are expressed as fold increase relative to preanoxia value. ${ }^{\#} P<0.05$ vs. vehicle; $n=4-10$ determinations

suggests that the endogenous burst of ROS induced by reoxygenation is too short and/or too weak to strongly activate the kinase, in contrast to the severe exogenous oxidant stress generated by $\mathrm{H}_{2} \mathrm{O}_{2}$ which markedly increased ERK phosphorylation. It should also be noticed that ERK activity measured in the ventricle did not vary during anoxia-reoxygenation (Sarre and Maurer, personal communication).

Since the publication of Bogoyevith et al. [43] in 1996, several studies confirmed that p38 is strongly activated in heart by ischemia and involved in response to hypoxia and anoxia, but whether it displays a beneficial or a detrimental role remains under debate $[44,45]$. In the present study, although the basal level of p38 expression was not homogeneous within the heart (Fig. 1b), anoxia increased phosphorylation in the three cardiac regions relative to preanoxic levels, especially in the outflow tract, (Fig. 3). Studies performed in adult [46, 47] and embryonic [9] cardiomyocytes showing that ROS production is totally abolished under strict anoxia, indicate that the observed anoxic increase of phospho-p38 was ROS-independent. The phosphorylation levels and kinase activities determined in this work displayed important interindividual variations which might be due to slight differences in developmental stage and/or to the relative sensitivity of the used techniques, including immunoblotting and kinase assay. Nevertheless, the greatest coefficient of variability of the level of p38 phosphorylation was consistently observed in ventricle and outflow tract after $10 \mathrm{~min}$ of reoxygenation. This suggests that during such a brief period of time, when ROS production is maximal, crucial cellular alterations may occur in these regions.

Although reoxygenation induces a calcium-dependent peak of JNK activity in the ventricle [20], we did not found the same pattern for JNK phosphorylation. Such a dissociation between JNK activity and phosphorylation could be partly related to the regulatory role played by scaffold proteins associated to JNK, e.g., JIP1, Sab, and Gst [48-50]. This important facet of JNK modulation is beyond the scope of our study. Likewise, an upward trend in JNK activity was observed in atria and outflow tract after 30-40 min reoxygenation, but without statistical significance.

We have previously shown that pharmacological opening of mitoK $\mathrm{ATP}_{\mathrm{AT}}$ channels not only reduces the reoxygenationinduced peak of JNK activity [20] but also improves ventricular recovery through a ROS-dependent mechanism [9]. However, in the present study, we found that diazoxide did not reduce JNK phosphorylation in ventricle, indicating that the modulation of JNK activity by the open-state of the mitoK $\mathrm{K}_{\mathrm{ATP}}$ channels is not related to phosphorylation of the kinase, but rather to the level of intracellular calcium [20] and/or to alteration of JNK-interacting proteins (see above).

In conclusion, this study demonstrates for the first time that ERK, p38, and JNK show a characteristic distribution in the embryonic heart and are differentially modulated by anoxia-reoxygenation, exogenous oxyradicals, and mitochondrial $\mathrm{K}_{\mathrm{ATP}}$ channels in a region-specific manner. Even if the functional role of these MAP kinases remains to be clarified in such a model, our findings provide a first step in understanding the modulation of the signal transduction cascades in the developing heart subjected to oxygen lack and reoxygenation.

Acknowledgments The collaboration of Fabienne Maurer, Christophe Bonny, and Miguel Van Bemmelen, is gratefully acknowledged. We thank Anne-Catherine Thomas for her skillful technical assistance. This work was supported by the Swiss National Science Foundation $n^{\circ} 3100 \mathrm{~A} 0-105901$.

\section{References}

1. Ostadal B, Ostadalova I, Dhalla NS (1999) Development of cardiac sensitivity to oxygen deficiency: comparative and ontogenetic aspects. Physiol Rev 79:635-659

2. Raddatz E, Gardier S, Sarre A (2006) Physiopathology of the embryonic heart (with special emphasis on hypoxia and reoxygenation). Ann Cardiol Angeiol (Paris) 55:79-89

3. Jensen A, Garnier Y, Berger R (1999) Dynamics of fetal circulatory responses to hypoxia and asphyxia. Eur J Obstet Gynecol Reprod Biol 84:155-172 
4. Sharma SK, Lucitti JL, Nordman C, Tinney JP, Tobita K, Keller BB (2005) Impact of hypoxia on early chick embryo growth and cardiovascular function. Pediatr Res 59:116-120

5. Fowden AL, Giussani DA, Forhead AJ (2006) Intrauterine programming of physiological systems: causes and consequences. Physiology 21:29-37

6. Ream M, Ray AM, Chandra R, Chikaraishi DM (2008) Early fetal hypoxia leads to growth restriction and myocardial thinning. Am J Physiol Regul Integr Comp Physiol 295:R583-R595

7. Agata N, Kato Y, Tanaka H, Shigenobu K (1994) Differential effects of hypoxia on electrical and mechanical activities of isolated ventricular muscles from fetal and adult guinea-pigs. Gen Pharmacol 25:15-18

8. Kasuya Y, Matsuki N, Shigenobu K (1977) Changes in sensitivity to anoxia of the cardiac action potential plateau during chick embryonic development. Dev Biol 58:124-133

9. Sarre A, Lange N, Kucera P, Raddatz E (2005) mitoK ATP $_{\text {channel }}$ activation in the postanoxic developing heart protects E-C coupling via NO-, ROS-, and PKC-dependent pathways. Am J Physiol Heart Circ Physiol 288:H1611-H1619

10. Sarre A, Maury P, Kucera P, Kappenberger L, Raddatz E (2006) Arrhythmogenesis in the developing heart during anoxia-reoxygenation and hypothermia-rewarming: an in vitro model. J Cardiovasc Electrophysiol 17:1350-1359

11. Raman M, Chen W, Cobb MH (2007) Differential regulation and properties of MAPKs. Oncogene 26:3100-3112

12. Wang Y (2007) Mitogen-activated protein kinases in heart development and diseases. Circulation 116:1413-1423

13. Bogoyevitch MA (2000) Signalling via stress-activated mitogenactivated protein kinases in the cardiovascular system. Cardiovasc Res 45:826-842

14. Liberatore CM, Yutzey KE (2004) MAP kinase activation in avian cardiovascular development. Dev Dyn 230:773-780

15. Ravingerova T, Barancik M, Strniskova M (2003) Mitogenactivated protein kinases: a new therapeutic target in cardiac pathology. Mol Cell Biochem 247:127-138

16. Bell RM, Clark JE, Hearse DJ, Shattock MJ (2007) Reperfusion kinase phosphorylation is essential but not sufficient in the mediation of pharmacological preconditioning: characterisation in the bi-phasic profile of early and late protection. Cardiovasc Res 73:153-163

17. Hausenloy DJ, Yellon DM (2006) Survival kinases in ischemic preconditioning and postconditioning. Cardiovasc Res 70: 240-253

18. Schulz R (2005) A new paradigm: cross talk of protein kinases during reperfusion saves life!. Am J Physiol Heart Circ Physiol 288: $\mathrm{H} 1-\mathrm{H} 2$

19. Tenhunen O, Soini Y, Ilves M, Rysa J, Tuukkanen J, Serpi R et al (2006) p38 kinase rescues failing myocardium after myocardial infarction: evidence for angiogenic and anti-apoptotic mechanisms. FASEB J 20:1907-1909

20. Sarre A, Gardier S, Maurer F, Bonny C, Raddatz E (2008) Modulation of the c-Jun N-terminal kinase activity in the embryonic heart in response to anoxia-reoxygenation: involvement of the $\mathrm{Ca}^{2+}$ and mitoK ${ }_{\text {ATP }}$ channels. Mol Cell Biochem 313:133-138

21. Romano R, Rochat AC, Kucera P, De Ribaupierre Y, Raddatz E (2001) Oxidative and glycogenolytic capacities within the developing chick heart. Pediatr Res 49:363-372

22. Moorman AF, Schumacher CA, de Boer PA, Hagoort J, Bezstarosti K, van den Hoff MJ et al (2000) Presence of functional sarcoplasmic reticulum in the developing heart and its confinement to chamber myocardium. Dev Biol 223:279-290

23. Tenthorey D, de Ribaupierre Y, Kucera P, Raddatz E (1998) Effects of verapamil and ryanodine on activity of the embryonic chick heart during anoxia and reoxygenation. J Cardiovasc Pharmacol 31:195-202

24. Franco D, Gallego A, Habets PE, Sans-Coma V, Moorman AF (2002) Species-specific differences of myosin content in the developing cardiac chambers of fish, birds, and mammals. Anat Rec 268:27-37

25. Raddatz E, Thomas AC (2002) Heterogeneity of oxydant stress in the reoxygenated developing heart. J Mol Cell Cardiol 34:A52

26. Maury P, Sarre A, Terrand J, Rosa A, Kucera P, Kappenberger L et al (2004) Ventricular but not atrial electro-mechanical delay of the embryonic heart is altered by anoxia-reoxygenation and improved by nitric oxide. Mol Cell Biochem 265:141-149

27. Shrier A, Clay JR (1982) Comparison of the pacemaker properties of chick embryonic atrial and ventricular heart cells. J Membr Biol 69:49-56

28. Zarubin T, Han $\mathrm{J}$ (2005) Activation and signaling of the p38 MAP kinase pathway. Cell Res 15:11-18

29. Hamburger V, Hamilton H (1951) A series of normal stages in the development of the chick embryo. J Morphol 88:49-92

30. Larsen CM, Wadt KA, Juhl LF, Andersen HU, Karlsen AE, Su MS et al (1998) Interleukin-1beta-induced rat pancreatic islet nitric oxide synthesis requires both the p38 and extracellular signal-regulated kinase 1/2 mitogen-activated protein kinases. J Biol Chem 273:15294-15300

31. Martinsen BJ (2005) Reference guide to the stages of chick heart embryology. Dev Dyn 233:1217-1237

32. Sugishita Y, Leifer DW, Agani F, Watanabe M, Fisher SA (2004) Hypoxia-responsive signaling regulates the apoptosis-dependent remodeling of the embryonic avian cardiac outflow tract. Dev Biol 273:285-296

33. Barbosky L, Lawrence DK, Karunamuni G, Wikenheiser JC, Doughman YQ, Visconti RP et al (2006) Apoptosis in the developing mouse heart. Dev Dyn 235:2592-2602

34. Lee K, Esselman WJ (2002) Inhibition of PTPs by $\mathrm{H}(2) \mathrm{O}(2)$ regulates the activation of distinct MAPK pathways. Free Radic Biol Med 33:1121-1132

35. Guyton KZ, Liu Y, Gorospe M, Xu Q, Holbrook NJ (1996) Activation of mitogen-activated protein kinase by $\mathrm{H}_{2} \mathrm{O}_{2}$. Role in cell survival following oxidant injury. J Biol Chem 271:4138-4142

36. Griendling KK, Sorescu D, Lassegue B, Ushio-Fukai M (2000) Modulation of protein kinase activity and gene expression by reactive oxygen species and their role in vascular physiology and pathophysiology. Arterioscler Thromb Vasc Biol 20:2175-2183

37. Barsacchi R, Camici P, Bottigli U, Salvadori PA, Pelosi G, Maiorino $M$ et al (1983) Correlation between hydroperoxideinduced chemiluminescence of the heart and its function. Biochim Biophys Acta 762:241-247

38. Sabri A, Byron KL, Samarel AM, Bell J, Lucchesi PA (1998) Hydrogen peroxide activates mitogen-activated protein kinases and $\mathrm{Na}^{+}-\mathrm{H}^{+}$exchange in neonatal rat cardiac myocytes. Circ Res 82:1053-1062

39. Nakamura TY, Goda K, Okamoto T, Kishi T, Nakamura T, Goshima K (1993) Contractile and morphological impairment of cultured fetal mouse myocytes induced by oxygen radicals and oxidants. Correlation with intracellular $\mathrm{Ca}^{2+}$ concentration. Circ Res 73:758-770

40. Fisher SA (2007) The developing embryonic cardiac outflow tract is highly sensitive to oxidant stress. Dev Dyn 236:3496-3502

41. Knight RJ, Buxton DB (1996) Stimulation of c-Jun kinase and mitogen-activated protein kinase by ischemia and reperfusion in the perfused rat heart. Biochem Biophys Res Commun 218:83-88

42. Ruusalepp A, Czibik G, Flatebo T, Vaage J, Valen G (2007) Myocardial protection evoked by hyperoxic exposure involves signaling through nitric oxide and mitogen activated protein kinases. Basic Res Cardiol 102:318-326 
43. Bogoyevitch MA, Gillespie-Brown J, Ketterman AJ, Fuller SJ, Ben-Levy R, Ashworth A et al (1996) Stimulation of the stressactivated mitogen-activated protein kinase subfamilies in perfused heart. p38/RK mitogen-activated protein kinases and c-Jun $\mathrm{N}$-terminal kinases are activated by ischemia/reperfusion. Circ Res 79:162-173

44. Bassi R, Heads R, Marber MS, Clark JE (2008) Targeting p38MAPK in the ischaemic heart: kill or cure? Curr Opin Pharmacol 8:141-146

45. Clerk A, Sugden PH (2006) Inflame my heart (by p38-MAPK). Circ Res 99:455-458

46. Hoffman DL, Salter JD, Brookes PS (2007) Response of mitochondrial reactive oxygen species generation to steady-state oxygen tension: implications for hypoxic cell signaling. Am J Physiol Heart Circ Physiol 292:H101-H108

47. Wang W, Fang H, Groom L, Cheng A, Zhang W, Liu J et al (2008) Superoxide flashes in single mitochondria. Cell 134:279-290

48. Nihalani D, Wong HN, Holzman LB (2003) Recruitment of JNK to JIP1 and JNK-dependent JIP1 phosphorylation regulates JNK module dynamics and activation. J Biol Chem 278:28694-28702

49. Adler V, Yin Z, Fuchs SY, Benezra M, Rosario L, Tew KD et al (1999) Regulation of JNK signaling by GSTp. EMBO J 18:13211334

50. Wiltshire C, Gillespie DA, May GH (2004) Sab (SH3BP5), a novel mitochondria-localized JNK-interacting protein. Biochem Soc Trans 32:1075-1077 